\title{
O QUE ME TORNA INVISÍVEL? A PSICANÁLISE COMO FERRAMENTA PARA ENTENDER O "APAGAMENTO" DAS DIFERENÇAS NA INCLUSÃO ESCOLAR DE SURDOS
}

\author{
Vanessa Regina de Oliveira Martins
}

\section{RESUMO}

Este artigo irá apontar situações de invisibilidade - "sensação de apagamento" - vivenciadas por mim na sala de aula atuando como intérprete educacional de língua de sinais no ensino superior. A proposta é de fazer uma reflexão das minhas experiências empíricas protagonizadas neste contexto, de sala de aula inclusiva, dialogando, de forma interesseira e interessada, com os saberes da psicanálise. O objetivo é entender as causas que levam o "apagamento" do outro: se à explícita exclusão e extermínio da diferença ou se à uma forma de mascarar uma situação incômoda de inclusão como sendo algo aparentemente tranqüilo - aceito - mas, ainda assim caminhando para a exclusão do outro só que agora de uma forma sutil e discreta.

\section{PALAVRAS-CHAVE}

Intérprete de língua de sinais; Surdez; Diferença; Exclusão; Psicanálise

\section{WHAT IT BECOMES ME INVISIBLE? THE PSYCHOANALYSIS AS TOOL TO UNDERSTAND THE "DELETION" OF THE DIFFERENCES IN THE PERTAINING TO SCHOOL INCLUSION}

\begin{abstract}
This article will go to point situations of invisibilidade - "deletion sensation" - lived deeply by me in the classroom acting as educational interpreter of language of signals in higher education. The proposal is to make a reflection of my carried out empirical experiences in this context, of inclusive classroom, dialoguing, of interesseira form and interested party, with knowing them of the psychoanalysis. The objective is to understand the causes that take the "deletion" of the other: if for the explicit exclusion and extermínio of the difference or as one it forms to mask a situation bothers of inclusion as being something pparently calm - accepted - but, still thus walking for the exclusion it another one only that now of one it forms subtle and discrete.
\end{abstract}

\section{KEYWORDS}

Interpreter of Sign Language; Deafness; Difference; Exclusion; Psychoanalysis

(C) ETD - Educação Temática Digital, Campinas, v.8, n.esp., p.135-152, dez. 2006 - ISSN: 1676-2592 135 


\section{ARTIGO \\ Grupo de Estudos e Pesquisa Diferenças e Subjetividades em Educação Grupo de Leitura de Freud}

\section{INTRODUÇÃO}

\section{Apagaram as luzes: epa! ... há um surdo aqui!}

Compartilhando uma experiência...

Era uma aula, como outra qualquer, do curso de arquitetura e urbanismo em que interpretava diariamente. O tema proposto era “a história do movimento urbano”, da disciplina de Teorias do Urbanismo. Estava ali como de costume: sentada em frente ao aluno surdo e de costas para o professor que ficava alocado em uma plataforma em frente à lousa.

O professor havia proposto em aulas anteriores que os alunos formassem grupos para desenvolver um estudo sobre a arquitetura clássica; e como avaliação semestral, cada grupo ficaria responsável em configurar a apresentação de um seminário. Cada aula um novo estudo, até que chega o dia esperado da apresentação.

Anunciado o início dos seminários, os alunos, então, apresentariam o resultado do estudo e a escolha que fizeram do projeto (obra e cidade) e arquiteto. Cada grupo se posicionou para dar início à atividade. Tudo aparentemente tranqüilo!

Toda sala me enxergava!...Isso era o que eu, na minha inocência, acreditava. Meus braços já fadigados, de tanto sinalizar uma aula teórica e carregada de explicações orais dos grupos, quando... as luzes se apagaram! Que susto! Pensei e senti um desconforto imediatamente.

No meio do seminário uma das alunas do curso apagou a lâmpada que iluminava a sala para continuar a sua apresentação - a vergonha de falar em público fez com que ela tomasse tal atitude. O professor aceitou a situação passivamente e assim, a aula prosseguiu normalmente.

Surpreendida senti-me invisível! Na verdade éramos dois “apagados”: eu e o surdo que nessa hora não tinha sequer idéia do que estava acontecendo. Fiquei paralisada! Percebia o movimento desconcertado e eufórico do aluno surdo em busca de explicações para aquela situação na tentativa de visualizar algum movimento... meus sinais no escuro... no silêncio que a situação lhe impôs.

(C) ETD - Educação Temática Digital, Campinas, v.8, n.esp., p.135-152, dez. 2006 - ISSN: 1676-2592 136 


\section{ARTIGO \\ Grupo de Estudos e Pesquisa Diferenças e Subjetividades em Educação Grupo de Leitura de Freud}

Momentos depois ao acender das lâmpadas uma pergunta me veio em mente: Como puderam nos esquecer com tantos meses de contato? Como esqueceram que minhas mãos precisavam das luzes para dialogar com o aluno surdo? Por que o professor aceitou passivamente a situação; será que ele esqueceu que tem um surdo em sua sala?

Desta primeira experiência de invisibilidade proponho iniciar nossa conversa com a psicanálise e a filosofia. Trarei para reflexão algumas situações cotidianas, como a ilustrada anteriormente, em que se nota a invisibilidade do ato tradutório em sala de aula: o apagar da presença física de um estranho no contexto educacional. As ferramentas analíticas destes dois campos de saberes (psicanálise e filosofia) disponibilizarão recursos para o pensar das várias formas de apagamento da presença do outro: a exclusão inclusiva. Como articuladores deste estudo proponho refletir com os pensamentos e as teorias de Freud (Psicanálise) e Foucault (padrões normativos e anormalidades). E desta perspectiva proponho (re) visitarmos e comemorarmos, também, o momento histórico dos “150 anos de Freud” e da apropriação do conceito da psicanálise que atualmente vêm sendo convocada como instrumento de reflexão das angústias no âmbito escolar. 


\section{ARTIGO \\ Grupo de Estudos e Pesquisa Diferenças e Subjetividades em Educação Grupo de Leitura de Freud}

\section{INCLUSÃO DE SURDOS: REFLEXÕES FILOSÓFICAS}

A inclusão - como medida política adotada por grande parte dos países ocidentais instaura uma temática discursiva no campo educacional sobre o compromisso ético de se haver com a diferença e com as diferentes formas de ensinar e de aprender; além disso, nos interpele a re-significar a interação entre professor e aluno e a dinâmica escolar. Nesta perspectiva o educador se agencia em uma luta política de recebimento e acolhimento das diferenças na escola, permeadas por um conjunto de discursos que oficializam essa prática.

Num dos possíveis modelos proposto por essa via inclusiva de se “fazer” a escola, a inclusão toma como pressupostos discursivos - um conjunto de agenciamentos embasados por valores / signos que a fundamentam - a inserção e exibição da diferença; no movimento de divisão dos espaços comuns de ensino entre educandos “especiais” - alunos com deficiências, dificuldades de aprendizagem, distúrbios de aprendizagens, etc... - com os "ditos “normais".

Há implícita, nesta dinâmica, a existência de certa norma que diferencia e classifica essa dicotomia entre normal e especial, normal e "a-normal" ou ainda, normal e patológico; e deixa evidências de que esta escola - baseada na/da norma - permite a inclusão de todos. Tem, portanto, espaço para qualquer um desde que assumido uma classificação,nomeação nosográfica dentro da grade normativa. Foucault (2002) nos oferece subsídios para entender as relações sociais permeadas pela busca do poder; as representações nelas fundadas que se estabelecem nos discursos produzidos. Interpela-nos a suspeitar das verdades naturalizadas.

Esse mesmo autor ajuda-nos, ainda, a entender os diversos dispositivos de poderes articulados politicamente nas sociedades modernas, através das redes de agenciamentos normativas, - instaurada com o movimento da disciplina (docilização/domesticação do corpo) à regulamentação (normatização da população) - que viabilizam a ação de um outro poder social: o Biopoder e o Racismo de Estado.

As ações destes dois dispositivos, Biopoder e Racismo de Estado, aparecem nos estudos de Foucault (2002), no final do século XVIII e no início do XIX. Há um redirecionamento do objeto de interesse e de controle social, que propicia a constituição de

(c) ETD - Educação Temática Digital, Campinas, v.8, n.esp., p.135-152, dez. 2006 - ISSN: 1676-2592 138 
um conjunto de redes agenciadoras do "bem estar social”, do "movimento sanitarista” e da “industrialização”. Os mecanismos de poder que passam a controlar e cuidar da população aparecem constituídos na biopolítica - uma política do biológico - com a temática da purificação social - “a biopolítica lida com a população, e a população como problema político, como problema a um só tempo (...) como problema biológico e como problema de poder” (FOUCAULT, 2002, p.293).

Os mecanismos de controle social que refletem a forma de poder ganham proporções maiores, indo além do indivíduo - do corpo individualizado, controlado e vigiado -, para a massa social - unidade múltipla -, constituindo assim, as sociedades de controle emergentes que, cada vez mais, quantifica e nomeia um a um, setorizando o espaço arquitetônico ocupado pelo indivíduo na população. Então, nesse momento, vemos a ação do racismo de Estado aparecer; ação esta que reverbera na forma articulada em nível de “população”, de “rede social”, de “discurso em massa”.

É o racismo de Estado que contribui para o apagamento da diferença, de forma que "soberanamente" passa a controlar e escolher o que deve permanecer e o que deve desaparecer da sociedade - sempre com o discurso da coletividade e da "purificação" social partindo, no entanto, da exclusão de todo corpo não docilizado... não disciplinado... não normatizado... desaparece com todo corpo que queira encontrar gozo na diferença: da surdez, da loucura, da deficiência, da a-normalidade... O racismo age cruelmente na medida em que inviabiliza o surgimento de qualquer diferença mínima que seja. O Biopoder, agenciador do Racismo:

Opera por meio da série população-processos biológicos-mecanismos regulamentadores-Estado. Ora, se a disciplina opera no nível do detalhe, do corporal, do individual, por intermédio das instituições, o biopoder opera num nível mais global, atravessando as populações por meio do Estado... .... Na analítica foucaultiana, o racismo é o mecanismo pelo qual o Estado justifica seu direito de matar, numa sociedade biopolítica fundada na afirmação da vida. E o que é mais interessante: o direito de matar é justificado como uma afirmação da própria vida, uma vez que a eliminação do diferente, do menos dotado, do menos capaz implica a purificação da raça, o melhoramento da população como um todo. (GALLO \& SOUZA, 2002, p. 47) 
Nesta lógica foucaultiana faço pensar a educação - mais especificamente a educação inclusiva de surdos - como parte e efeito desse jogo discursivo de "poder" e "fazer" social. O educando inserido só é efeito na inclusão porque passa a manter relação de (re) conhecimento em um subconjunto normativo, passando a ser seriado e classificado dentro de um grupo de representações conceituais discursivas que lhe atribui significados as suas (a) normalidades. Assim, a inclusão passa a ter papel fundamental para o controle e inserção deste sujeito na sociedade, que a priori o nomeia segundo suas diferenças ou estranhezas. Esse é um momento importante - a nomeação - que padroniza o que "é" este outro - uma nosografia do sujeito.

Para além desta discussão, neste artigo, faço pensar de que forma a inclusão, através deste paradigma atual contribui para a exclusão de sujeitos e de seus processos de subjetivação; e que contradiz, desta forma, a idéia primeira de inclusão de/para todos (pela não inclusão real). Posterior a essa inquietação, indago se há formas outras de pensar a inclusão para além da que temos atualmente: a inserção de diferentes corpos ou de corpos diferentes num espaço comum de ensino. É possível pensar na inclusão da diferença na escola? Se sim, porque sinto em minhas experiências vários momentos de apagamento da diferença espelhados na atuação do intérprete de língua de sinais em conjunto ao apagamento do surdo e da surdez? Podemos pensar que há nisso - na inclusão a ação do Biopoder, expressa por Foucault (2002), e que sutilmente produz formas políticas de "apagamento" da diferença para garantir uma igualdade normativa?

Acredito que há indícios para se pensar por este caminho - na ação do biopoder e do apagamento das diferenças que parecem estar a serviço desta política inclusiva - embora, no momento, não tenha possibilidade de fechar nenhuma resposta. O que faço é propor a desconstrução conceitual - de norma, inclusão, exclusão - que tomamos hoje como constructo de verdade. Refinar o olhar para além dessa política instaurada, tomando como processo a reflexão nas micro-políticas e nas micro-instâncias, que vão para além do discurso legislativo imposto, voltando-se as ações que surgem das práticas cotidianas da inclusão numa instancia micro educacional. Esses discursos que, pensando com Foucault (1996), não são neutros, ao refletirem os vários movimentos e interesses de busca pelo 


\section{ARTIGO \\ Grupo de Estudos e Pesquisa Diferenças e Subjetividades em Educação Grupo de Leitura de Freud}

poder; e por isso a necessidade de questionamento das verdades criadas pelos homens e difundidas nas sociedades é de extrema relevância.

O discurso - como a psicanálise nos mostrou - não é simplesmente aquilo que manifesta (ou oculta) o desejo; é, também aquilo que é o objeto do desejo; e visto que - isto a história não cessa de nos ensinar - o discurso não é simplesmente aquilo que traduz as lutas ou os sistemas de dominação, mas aquilo por que, pelo que se luta, o poder do qual nos queremos apoderar. (FOUCAULT, 1996, p. 10)

Como é que estamos trabalhando com/para as diferenças? Há possibilidade de se criar processos de subjetivação dos múltiplos sujeitos que a escola, nomeada "para todos"a escola inclusiva - se propõe a fazer? Estamos questionando os discursos produzidos para este fim?

Como proposta inclusiva, a presença da diferença (caracterizado aqui pela surdez) favorece a interação e aprendizagem do educando no grupo; e muitas vezes vemos “bandeiras” alçadas da inclusão pela inclusão - que é a valorização da socialização entre alunos especiais e "normais” num contexto educacional e que se propõe viabilizar através das trocas - sem um olhar crítico das “exclusões” que ela pode proporcionar.

Como a comunicação entre ouvintes e surdos sinalizadores é inviabilizada sem a utilização da língua de sinais, a inserção em si, neste caso, de nada adianta sem a presença de um intermediário - o intérprete de língua de sinais (ILS) ou de um professor fluente em Libras. E mais, não é consenso geral de que esta inclusão atente aos desejos destes surdos sinalizadores. Então, se pensarmos que vários surdos universitários se mantém inseridos em uma universidade sem a presença de intérpretes e, portanto sem a veiculação da Libras, fica a seguinte pergunta: quais os saberes que estão sendo construídos na formação deste educando? A que está servindo esta inclusão, senão para apagar a alteridade surda e sua diferença? Como deixar de reconhecer a necessidade de outras formas metodológicas e curriculares que são convocadas pela surdez?

Sobre isso afirmo que o real sentido da inclusão, - o entendimento que para incluir é preciso mudar concepções - não a de corpos, mas a de trocas efetivas de saberes culturais, que é o objetivo maior da instituição escolar - a inclusão formadora - ainda não parece estar sendo viabilizada e compreendida. E por isso mantêm-se práticas que tendem a 


\section{ARTIGO \\ Grupo de Estudos e Pesquisa Diferenças e Subjetividades em Educação Grupo de Leitura de Freud}

transformar as diferenças em unidades iguais sistematizadas; o surdo em um "quase" ouvinte e um "quase” falante, que aprende da mesma forma metodológica que os demais. Nisso a diferença primeira da surdez, que o constitui em sujeito visual e usuário de uma língua de modalidade distinta a dos ouvintes, é simplesmente esquecida.

Como modificar esse espaço de inclusão “apagadora” que: exclui, disciplina, modifica e igualiza a diferença? Utilizo a pergunta do autor como gancho na reflexão:

Si la tríada modulación-control-exclusión va desplazando del escenario al binômio disciplinamento-inclusión, la pergunta acerca de la espacialidad del otro y de la otra espacialidad asume un particular significado: Hay lugares no modulados, de no-control, de no-exclusión, que no sean lugares de disciplimamiento y de inclusión? ¿Hay, acaso, una suerte de tercer espacio, un espacio sin nombre, un entre-lugar, es decidir, un espacio otro, un otro espacio? (SKLIAR, 2002:89-90)

Estas são algumas formas políticas de apagar o outro e que várias vezes preenchem o campo discursivo como ações “politicamente corretas”. Há que se convocar urgentemente novas formas de pensar a inclusão escolar - sem que para isso tenhamos que normatizar o outro - podendo sofrer alterações na compreensão do que seja incluir, num movimento às avessas.

\section{REFLEXÕES COTIDIANAS: PORQUE ME APAGARAM?}

Compartilhando experiências com o auxílio da psicanálise...

\footnotetext{
Quando já se viveu por muito tempo numa civilização específica e com freqüência se tentou descobrir quais foram suas origens e ao longo de que caminho ela se desenvolveu, fica-se às vezes tentado a voltar o olhar para outra direção e indagar qual o destino que a espera e quais as transformações que está fadada a experimentar. (FREUD, 1974:15)
}

Continuando nossa conversa, agora convocando a psicanálise, como ferramenta e chave de leitura para reflexão das experiências empíricas vivenciadas na sala de aula de ensino superior, onde atuo diariamente como intérprete de língua de sinais. Aproveito para 
marcar a importante contribuição da psicanálise - como ferramenta analítica sobre o “desejo/ prazer”, a "linguagem”, a “falta” - nos processos de reflexão da práxis docente. Os saberes psicanalíticos contribuem de forma ampla no entendimento das relações de transferência e contratransferência no processo de ensino e aprendizagem (professor e aluno). E ainda, coloca-nos a pensar, o que de fato, é o “acontecimento do ensino/ a prática docente” e as formas de “encaixe”, entre professor e aluno, necessárias para que se estabeleça a aula e que ocorra a aprendizagem.

Esse movimento de olhar em rumo à transformação numa nova proposta de pensar a ação docente, com a ajuda da psicanálise, permite ao educador mirar a aula como um contrato entre alunos e professores - selados pelo desejo de estar ali, seja para ensinar ou para aprender. Esse desejo insistente e instigante é sinalizado pela falta... Falta essa - para o sujeito - que não se esvaece, mas que é alimentada pela constante busca de um encontro, de uma completude. A aula pode ser vista como esse encontro; um encontro na falta que cada um (professor e aluno) mantém e que ilusoriamente se completa na relação transferencial estabelecida neste contexto de ensino - na fantasia do ensino - (BEHARES, 2004).

Interessante notar que a experiência docente, com a inserção do intérprete de língua de sinais, quebra a lógica formulada desse pensamento psicanalítico elaborado sobre o ensino, pois passa a ocorrer através de um triângulo (professor, intérprete e aluno surdo) transferencial de desejos e encontros na falta. Faz-se pelo suposto saber que cada um tem e que falta ao outro e assim, de alguma forma, movimenta esse jogo de sedução e de ensino. A relação de transferência, neste caso particular, não ocorre de forma direta entre professor e aluno. O elemento terceiro (intérprete de língua de sinais - ILS) é que conduzirá esse jogo de desejos por ter “nas mãos” o elo - a língua que interpela e que potencializa a relação de afetividade na interação professor e aluno. A aprendizagem, o saber que o aluno quer se “nutrir”, e que motiva sua permanência na sala de aula, perpassa a mão/ o corpo do ILS. Desse contato direto há a instauração do processo de transferência entre ILS e aluno surdo - o encontro do desejo que movimenta cada um a estar ali é enlaçado.

Há por esse via, uma relação docente marcada na atuação do intérprete educacional diferente da atuação e da relação entre ILS e surdos em outra situação não escolar. Ora, se é entre o ILS e o surdo que se estabelece a relação afetiva no ensino, que outra coisa esse 
profissional faz se não de estabelecer uma relação docente; de ser um educador? Terá ele (ILS) apenas o papel de tradutor, ou também exerce uma relação de docência? Não pode nisso marcar uma inclusão - excludente, quando ajuda a compor a segregação de dois estranhos (ILS e surdo) num contexto coletivo de ensino em que o professor pouco sabe das necessidades educativas e metodológicas que estão ali convocadas? Será que o professor sente "familiar prazer" em educar um aluno que não fala sua língua? Apagar, esquecer e tolerar a "não familiaridade" é melhor que enfrentar o desconhecido e o desprazer de não saber como mediar por si o ensino sem a Libras (Língua Brasileira de Sinais)?

Deixo claro que não tenho nenhum intuito de culpabilizar a ação dos professores como fim em si. Acredito que os educadores são efeitos de um processo social de apagamento das diferenças, como pensado anteriormente. Há um contexto amplo, uma política agenciadora deste apagamento - o Estado que convoca o Racismo da diferença - na qual a educação é um dos laços que compõe a rede.

Retomando a questão da atuação do ILS, quero alocar este profissional como um dos facilitadores da inclusão dos surdos no ensino superior (mediador da comunicação). Faço um paralelo desta atividade como "tapa buraco" de uma situação de segregação omissa que a inclusão instaura dentro da sala de aula, tornando a atuação quase que uma aula particular.

O ponto no qual fixo o olhar é: embora imprescindível a presença do ILS em sala de aula (pensando que no momento atual, com a inclusão de surdos sinalizadores, o ILS tem um papel importante: o de manter o aluno supostamente integrado na instituição), há uma aparente invisibilidade - mesmo com toda a movimentação corporal, expressiva, gestual marcada na educação e expressa no relato que compartilhei acima. O primeiro contato do professor com o ILS é de espanto, admiração e desconhecimento. Passado um tempo, o trabalho vai ficando solitário entre ILS e o surdo: distante da sala... distante dos olhos dos professores e dos alunos... distante até da universidade que nos contrata e que, acreditando em nosso trabalho "ético", deixa em nossas mãos as ações educativas que achamos pertinentes aos surdos. Essa liberdade aparente, acaba durante a avaliação, pois descobrimos que não temos poder algum de mudança metodológica ou estrutural. Ficamos limitados às normas que igualam todas as ações gerais, incluindo as de ensino. 
A experiência, relatada no início do artigo, representa uma situação de apagamento dentre tantas outras nas quais me senti invisível ao sistema de ensino. Faço recair as seguintes perguntas: até que ponto o ILS possibilita a integração do aluno surdo, ou melhor, a visibilidade do surdo e suas necessidades na dinâmica escolar? Porque o professor - ou ainda podemos ampliar para a instituição - ainda não tinha incorporado o aluno surdo e suas especificidades de aprendizagem em sua ação docente?

Pensando com a psicanálise, segundo Freud (1974), com a descoberta do conceito de inconsciente, a humanidade passa pela terceira ferida narcísica ${ }^{1}$, chamada também de "golpe psicológico". Essa descoberta revela ao homem o desconhecimento de si mesmo, e por isso o total descontrole das ações que outrora eram pensadas como conhecidas, mapeadas e controladas. Causa-nos medo da diferença e de nela encontrarmos também gozo - já que o que pensávamos controlar, nós mesmo, é senão uma não-verdade.

Abre caminho para pensarmos que sempre haverá em nossas atitudes falhas que nos escapam e que não damos conta de conhecê-las. São, muitas vezes, conteúdos recalcados no inconsciente que surgem em dados momentos e nos colocam em (des) ajustes mediante diversas situações e, portanto, interfere na forma de nos relacionarmos com os outros.

No processo educativo - pensando na educação como nutrição, como completude da falta para além da questão biológica-orgânica - a psicanálise, nos convida a olhar a trama elaborada na relação de transferência e contratransferência psíquica entre educador e educando, que perpassa por um conjunto de formulações, fantasiosas/simbólicas, neste jogo relacional de desejo pelo ensino, ou ainda, de prazer no ensino, no qual o inconsciente é personagem. De certa forma comanda e determina as formas de lidar com o outro/Outro uma descoberta (des) prazerosa que cada envolvido (professor e aluno) estabelece e é movido pelo desejo de aprender e de ensinar.

Desta forma, o esquecimento do professor na experiência citada pode nos mostrar dados de "escapes”, de "Des-prazer" - que denuncia a ausência de "colagem simbólica”,

\footnotetext{
${ }^{1}$ Na “Conferência XVII - Fixação em Traumas” de 1917, Freud fez referência aos três severos golpes sofridos pelo homem no que tange seu "amor próprio" e seu no "narcisismo universal". O primeiro ocorreu com Copérnico e seu "golpe cosmológico", quando a terra deixou de ser vista como o centro do universo. O segundo, com Darwin e seu "golpe biológico", quando o homem deixou de ter uma ascendência divina sobre
}

(C) ETD - Educação Temática Digital, Campinas, v.8, n.esp., p.135-152, dez. 2006 - ISSN: 1676-2592 145 
um não encontro - a não marcação de um laço fraterno, como a que ocorre, se possível pensar, entre ILS e surdos. Para Lacan, "é a negação do estrangeiro que une os semelhantes; é a segregação que funda a fraternidade” (KOLTAI, 2000: 98).

O esquecimento pode ser uma forma de recusa sutil desta inclusão (“do nãofamiliar”) posta e que o professor não sabe como lidar, mas que eticamente não pode negar; antes deve aceitar e inserir o diferente - mesmo que por tolerância a diferença. Por não manter uma relação transferencial direta com o aluno surdo - barrado pela diferença estrutural da língua - o desejo, nesta erótica de ensino, passa a não acontecer de forma natural - acontecendo através da mediação do intérprete de língua de sinais. O desejo de saber o que o outro tem e que lhe falta (aluno/professor) - relação que ocorre na ação pedagógica - é redirecionado na pessoa do ILS.

Como resposta a esta nova dinâmica, muitas vezes desconhecida para o professor, há uma inversão de papéis: o professor deixa de exercer sua função de educador ao atribuir valores ao ILS, como se, neste lugar, ele (intérprete) suprisse a falta que mantém a relação ilusória de ensino - da Erótica de Ensino (BEHARES, 2006) - e que coloca o aluno surdo na posição de educando ou aprendiz.

Esquecer o surdo e em conseqüência o ILS parece ser uma forma de esquecer a sua ineficácia (não conhecimento da língua de sinais), neste contexto, como educador que tem a responsabilidade de agenciar as trocas de saberes do aluno surdo no contexto educacional. Essa situação é, sem dúvida, um sofrimento imposto ao professor e que, de alguma forma, o “organismo” tenta minimizar - esta causa dolorosa -, podendo, assim, fazer através do recalque.

Então, podemos entender que, também, há certa felicidade do professor com a chegada do ILS; a medida em que vem "tapar o buraco" do sofrimento, minimizar a dor e mediar a relação professor e aluno surdo. Nesta relação se estabelece um triângulo transferencial de desejos. O ILS, um mediador educacional que pode ser visto como um mal necessário para o surdo e para o professor. Um "entre” que configura a relação de ensino e que também faz o ensino.

os animais. E o terceiro, finalmente, com Freud sobre o Inconsciente e seu "golpe psicológico", quando deixamos de ser "senhores de nossa própria casa". (FREUD, 1976:335) 
Se a educação, para a psicanálise é uma necessária ilusão de ensino, a educação mediada pelo intérprete passa por um processo de ilusão ainda maior. O ILS acredita que o surdo está entendendo o que ele traduz, o surdo acredita que o ILS tem o saber que lhe falta e que este se apropria das minúcias da fala do professor ao traduzir e, para completar este ciclo, o professor acredita que o ILS e o aluno surdo estão em consonância com as suas explicações. Essa é a erótica de ensino criada na inclusão educacional de surdos mediada pelo ILS.

Esta inclusão ilusória falha, já que todo ensino é também uma ilusão necessária? Podemos pensar respostas possíveis a partir da contribuição discursiva do autor na citação abaixo. Suas colocações nos apontam explicações sobre os problemas susceptíveis em relação à educação dos surdos, e que, neste contexto muito pode contribuir com as questões discutidas:

\begin{abstract}
Es conveniente señalar lo que ha venido siendo repetido en los últimos cuarenta años: el déficit o la carencia de los sordos no es inmediatamente el derivado de una marca en el cuerpo, sino en su relación con el lenguaje. El Real de la sordera, lo sordo, no es el Real de la audición (en tanto que marca física en el cuerpo), por lo menos en aquello que pugna por manifestarse en nuestras representaciones occidentales, sino un Real del lenguaje y de la palabra. No es extraño, entonces, que la erótica que funda la intersubjetividad educador-educando en la educación del sordo se refiera a esta falta constitutiva. Sin lugar a dudas, hay en el campo de la educación de los sordos una fantasía "frustrogénica", particularmente regida desde el imposible absoluto de educar freudiano, que hace convivir discursivamente un no-se-puede y los forcejeos de rehabilitación y restitución del hablante, pero también, a mi entender, a las concesiones diferencialistas de matriz sociológica que honesta pero engañadamente creen haber dado un paso adelante. No lo han hecho plenamente, ${ }^{2}$ en efecto, porque reformulan en su base un imaginario de la sordera y del sujeto sordo (y también de su enseñanza y de su enseñante oyente o sordo), pero no toman en cuenta lo ideológico-estructural ni lo inconsciente-estructural de lo sordo ni de lo oyente. (BEHARES, 2006:240)
\end{abstract}

Finalizo afirmando que o problema posto, nesta forma atual de "fazer a inclusão", é a permanência do olhar reducionista de inclusão como simples manutenção de corpos que usufrui um mesmo espaço de ensino, sem, no entanto, questionar as especificidades que constitui cada um sujeito da/na diferença. É ainda, não problematizar as questões de ensino intrínseco na relação mediada pelo ILS e que são esquecidas por postular que a solução da

\footnotetext{
${ }^{2}$ Esto no implica negar que desde un punto de vista pedagógico-político las posturas hacia la Educación Bilingüe sean las más adecuadas y humanamente posibles, sino ampliar las discusiones en torno a lo que existe de todos modos más allá de ellas.
} 


\section{ARTIGO \\ Grupo de Estudos e Pesquisa Diferenças e Subjetividades em Educação Grupo de Leitura de Freud}

inclusão se faz apenas com a inclusão deste mediador; deixando de rever as mudanças necessárias no currículo e numa outra metodologia de ensino que priorize o "olhar” conceito que coloco para representar a metodologia de ensino para surdos, que são sujeitos constituídos por uma língua espaço-gesto-visual. E ainda, não consultar aos protagonistas (surdos sinalizadores), se essa forma hoje de ensino e de inclusão, satisfaz seus desejos e permite a manutenção da sua diferença. Será que estamos agindo em direção a uma ética de ensino para estes surdos?

Enfim, tudo isso nos leva a acreditar que é preciso uma nova forma de pensar a inclusão educacional, numa proposta que viabilize a construção de saberes e conhecimentos por sujeitos diferentes, que aprendem de forma outra e que por isso necessitam de um ensino diferenciado para torná-los sujeitos de um ensino igual (no sentido do direito ao ensino com qualidade e que sejam apreendidos os conteúdos curriculares sistematizados). Uma inclusão que pode separá-los no espaço físico, mas que certamente construirá uma forma ética de entender e “fazer” o ensino da e na diferença. 


\section{CONSIDERAÇÕES FINAIS}

O movimento de refletir - trazendo como referencial uma experiência empírica em que me coloco como participante - a inclusão do aluno surdo, em questão, inserido no ensino superior, foi para mim articulador e facilitador da compreensão das partes do processo que busco aprofundar o estudo. Chamei atenção, neste trabalho, as formas de "apagamento" ou "disciplinamento" do outro; do corpo do intérprete de língua de sinais e do corpo surdo que se tornam algumas vezes imperceptíveis mesmo presentes em sala de aula.

Tentei movimentar o leitor a uma suspensão dos pré-conhecimentos estabelecidos e veiculados socialmente, caminhando para um novo olhar sobre a proposta do que seja incluir os surdos. Uma visão para além da inserção de corpos reabilitados e integrados na norma vigente, mas uma proposta de inclusão social a partir da construção ética da aceitação da diferença que ultrapassa qualquer busca de homogeneização e tolerância.

Para isso tomei como pressupostos analíticos os saberes da filosofia e da psicanálise, que permitiram entender os processos históricos construídos e as relações de poderes em que se vêem instrumentalizadas táticas homogeneizadoras e normatizadoras que classificam as diferenças buscando formas disciplinares de lidar com o outro. $\mathrm{O}$ Racismo, entendido como mecanismo de "apagamento" da diferença e das estranhezas do outro.

No primeiro momento a tentativa era de tecer as formas políticas que a sociedade encontra para nomear as diferenças como "a-normalidades", como algo que deve ser "consertado" ou "reabilitado". Nesta perspectiva coloquei a surdez neste amontoado discursivo e conceitual que a contemporaneidade, ainda nomeia como "deficiência”, - no sentido da falta de eficiência -, com valor menor, abaixo da linha normativa ou mesmo como ameaça à igualdade que move entorno da busca por uma "raça socialmente pura/ melhor".

No segundo momento o objetivo era de refletir na inclusão de surdos, mais voltada ao ensino superior; as relações de ensino articuladas com a presença do intérprete de língua de sinais - entendendo a atuação do ILS como a de um educador -; a relação triangular 
entre professor-intérprete-surdo, e as diferentes armadilhas que apagam a diferença surda e transformam essa inclusão - de forma perversa - em exclusão, não contribuindo na formação de subjetividades surdas.

Dessa forma convido a pensarmos juntos, novas formas de "fazer" a inclusão, através de um laço fraterno, no qual o desejo surdo seja respeitado. E que nos coloquemos abertos a "ver" o que estão nos "sinalizando". Só questionando os moldes atuais da inclusão é que descobriremos porque ainda existem "apagados", "marginalizados"e “excluídos” do sistema social de ensino.

É preciso acender as luzes! 


\section{REFERÊNCIAS}

BEHARES, L.E. "Enseñanza-aprendizaje revisitados. Un análisis de la fantasia didáctica" In: Didáctica mínima. Los acontecimientos del saber. Montevideo: Psicolibros Waslala, 2004.

, L.E. "La Enseñanza Em El Campo De La Sordera. Reflexões Desde la Teoria Del Acontecimiento Didáctico”. In: ETD (Educação Temática Digital). Vol. 7. n² 2, 228243p., 2006.

FOUCAULT, M. A ordem do discurso. São Paulo: Edições Loyola, 1996.

, M. Microfísica do Poder. Rio de Janeiro: Graal, 1979.

, M. Em Defesa da Sociedade. São Paulo: Martins Fontes, 2002.

FREUD, S. (1974). “O futuro de uma ilusão”. In: S. Freud Edição Standard brasileira das obras psicológicas completas de Sigmund Freud”, tradução J. Salomão, vol. 21, pp. 15-71). Rio de Janeiro: Imago. (Trabalho original publicado em 1927)

."Totem e Tabu”. In: Freud, Sigmund, Edição Standard Brasileira das Obras Completas de Sigmund Freud. Volume XIII. Rio de Janeiro: Imago 1974.

. "Conferência XVII - Fixação em Traumas”. In: Edição Standard Brasileira das Obras Psicológicas Completas de Sigmund Freud. Volume XVI, Rio de Janeiro: Imago, 1976.

. “O Estranho". In: Edição Standard Brasileira das Obras Psicológicas Completas de Sigmund Freud. Volume XVII. Rio de Janeiro: Imago, 1976.

GALLO, S. \& SOUZA, R. M. "Por que matamos o barbeiro? Reflexões preliminares sobre a paradoxal exclusão do outro” In: Revista Educação e Sociedade, Campinas, Sp,v.23, n. 79, 39-63p., ago.2002.

KOLTAI, C. Política e Psicanálise. O estrangeiro. São Paulo: Escuta, 2000.

SKLIAR, C. “Alteridades y pedagogias. O... ¿ Y si el otro no estuviera ahi?” In: Revista Educação e Sociedade, v.23, p.85-123, ago.2002. 

especialização em Psicopedagogia/Facinter-Unibem; mestranda em psicologia educacional pela faculdade de educação da Unicamp sob orientação da Profa. Dra. Regina Maria de Souza. Membro do GES (Grupo de Estudos Surdos) da Unicamp. Intérprete de língua de sinais da

UNIP no Curso de Arquitetura e Urbanismo.

E-mail: vanymartins@hotmail.com Telefone: 19-32870266

Artigo recebido em: 25/09/2006

Artigo para publicação em: 27/12/2006 